\title{
Fracture model for rockburst mitigation based on the strain energy concept
}

\author{
R. Zepeda ${ }^{1}$ and G. Krstulovic ${ }^{2}$ \\ ${ }^{1}$ Codelco, Chile \\ ${ }^{2}$ Universidad Central, Chile
}

\begin{abstract}
Rockbursts constitute an operational problem in deep excavations where many mitigation attempts using different methodologies were used without achieving workable, palliative strategies. The mitigation method with the highest number of bibliographic references is pre-conditioning of rocks prone to this phenomenon.
\end{abstract}

Pre-conditioning seeks to lower the strength of the rock, ideally by increasing the number of fractures in it, and by extension, increasing its deformation response to imposed stress.

The hydraulic fracturing technique or the use of explosives has been described in the literature as means to induce fractures in the rock mass just ahead of mining. The former method is the most popular in Chile.

To date, there is not enough analytical explanation on how pre-conditioning can mitigate rockburst occurrences. In this paper, the laws of classic mechanics are described in terms of the strain energy to explain the pre-conditioning effect on the rockburst phenomenon; and arising from this, possible limitations of the hydraulic fracturing technique currently in use.

\section{INTRODUCTION}

There is consensus among specialists regarding rockbursts occurring in competent rocks with little or no natural fracturing in high stress environments. Therefore, mitigation of this phenomenon could be achieved using three strategies:

- Modifying the high stress environment of the rocks by changing the geometry of the mining method that influences them in such a way that it generates lower stress conditions.

- Increasing the rock fractures and, by extension the deformational capabilities in terms of Young's Modulus. This method is known as rock mass pre-conditioning and works by lowering the strength of the rock and its ability to store strain energy. Hydraulic fracturing is a pre-conditioning technique used in El Teniente, Landeros and Rojas (2017).

- Using both strategies simultaneously.

With regard to the rockburst phenomenon, rock deterioration is a concept that has not been sufficiently elaborated in classic rock mechanics. Nevertheless, in empirical terms, the authors propose a $\mathrm{RQD} / \mathrm{FF} / \mathrm{Em}$ (in-situ)/Er (laboratory) relation as shown in Figure 1, assuming that: 
- Maximum rockburst potential: RQD 90-100\%, less than $5 \mathrm{FF} / \mathrm{m}$.

- Moderate rockburst potential: RQD 75-90\%, between 5 and $10 \mathrm{FF} / \mathrm{m}$.

- No rockburst potential: RQD 50-75\%, above $10 \mathrm{FF} / \mathrm{m}$.

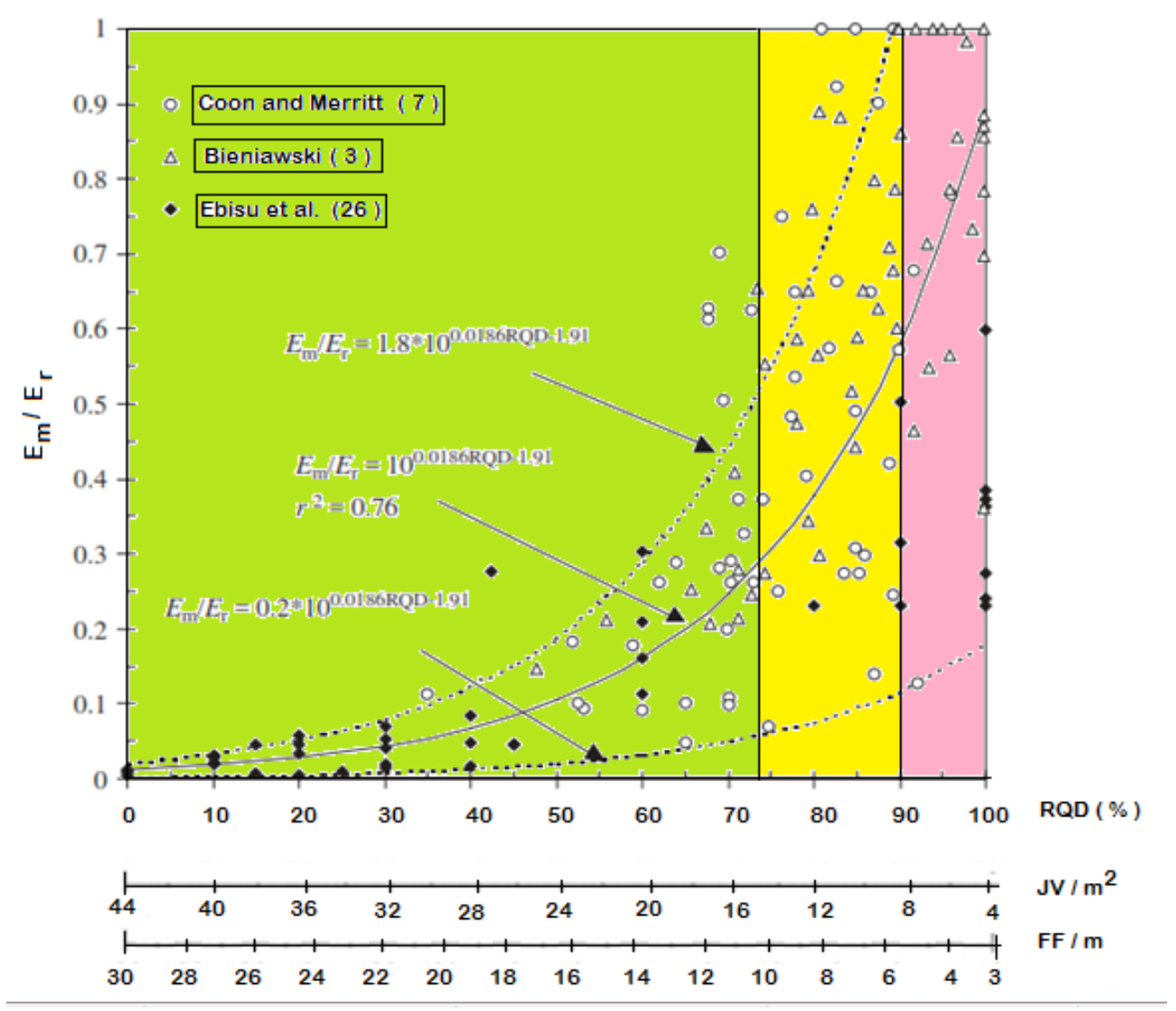

Figure 1. Empirical RQD / FF / (E) abacus, modified from Lianyang and Einstein (2004)

\section{ROCKBURST ANALYTICAL EXPRESSION IN STRAIN ENERGY TERMS}

Mining underground excavations causes a redistribution of stress in the contours of such excavations. The stress variations translate into different effects within the rock mass:

Variations in temperature. This effect is nearly imperceptible due to the rapid dissipation in the surrounding medium.

Acoustic emissions caused by the micro-fracturing in the rock portions with less resistance. These micro-fractures cause a deterioration of the affected volume and, consequently, the local stress redistributes among the most competent neighbouring volumes. The authors assume that competent volumes that are not subject to micro-fractures are precisely the ones that end up generating rockbursts. Considering the above, it's doubtful whether one could detect rockburst locations based only on acoustic records.

These stress variations cause deformations in the rocks, i.e., deformations that translate into available strain energy which causes rockbursts if the rock quality allows it.

Regarding the above, it's suggested that strain energy figure can be correlated with the rockburst phenomenon and for this purpose it's necessary to determine the maximum strain energy figure at the 
moment of rockburst events. To determine such value, the rock may be considered as a cubic block of differential dimensions with stresses imposed.

The strain energy value is the work done by these forces when they deform the cube of magnitude (dl). The equation that governs the relation between the stresses magnitudes and strain energy was presented by Love (1927), considering tectonic stresses (that are not derived from strict gravitational action) and the rock's Young's modulus and Poisson's ratio.

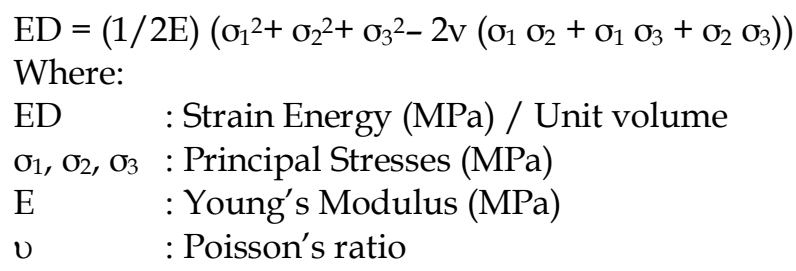

Other authors, such as Sirait et al (2013), simplify Love's original formulation for UCS tests so that:

$$
\mathrm{SED}=\sigma_{\mathrm{c}}^{2} / 2 \mathrm{E}
$$

Where:

SED : Strain Energy Density $(\mathrm{kJ} / \mathrm{m} 3)$

Where, $\sigma_{\mathrm{c}}$ is uniaxial compressive strength, and $\mathrm{E}$ is the elastic modulus. According to (Equation 2), weaker rocks can store less strain energy and are therefore less likely to burst. In this context Wang and Park (2001), illustrated Kwasniewski's work which scales the SED based on rockburst hazards as follows:

- $\mathrm{SED}=50 \mathrm{~kJ} / \mathrm{m}^{3}$, very low

- $50<\mathrm{SED}=100 \mathrm{~kJ} / \mathrm{m}^{3}$, low

- $100<\mathrm{SED}=150 \mathrm{~kJ} / \mathrm{m}^{3}$, moderate

- $150<\mathrm{SED}=200 \mathrm{~kJ} / \mathrm{m}^{3}$, high

- $\mathrm{SED}>200 \mathrm{~kJ} / \mathrm{m}^{3}$, very high

In the authors' opinion, this first approximation could be insufficient if SED is re-calculated using Love's complete formulation in triaxial tests. For example, El Teniente's CMET-type rocks (which are prone to rockbursts) have an average UCS value of $150 \mathrm{MPa}$, an average E value of $53 \mathrm{GPa}$ and 0.2 Poisson modulus that produce a SED value of $220 \mathrm{~kJ} / \mathrm{m}^{3}$. The same CMET rock, when analysed in triaxial tests and variable confinement between 4 and $10 \mathrm{MPa}$, generates explosive ruptures (rockbursts) under $150 \mathrm{~kJ} / \mathrm{m}^{3}$ (See Figure 2).

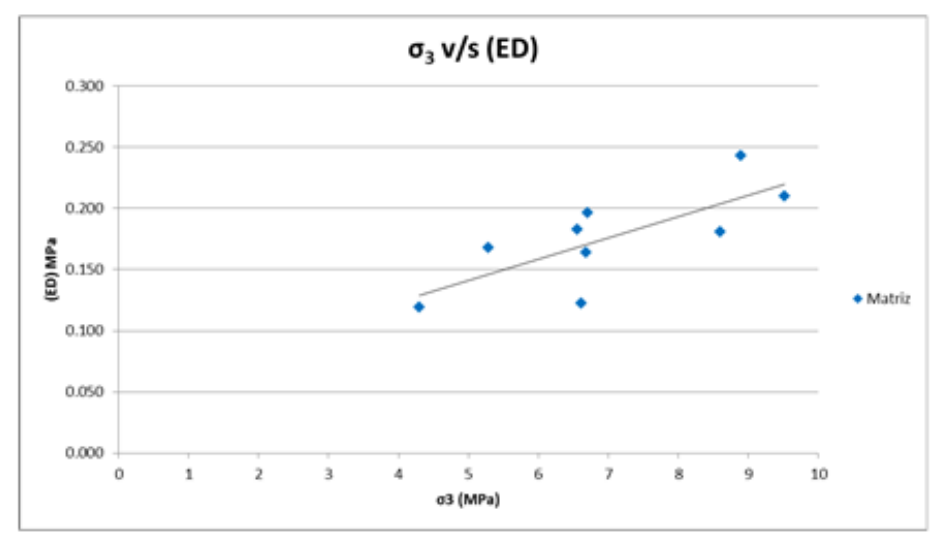

Figure 2. SED vs Confinement plot 
In any event, regardless of the above, in order to reduce rockburst tendency from SED $150 \mathrm{~kJ} / \mathrm{m}^{3}$ (moderate risk) to $50 \mathrm{~kJ} / \mathrm{m}^{3}$ (low risk), the strain energy for CMET must be reduced by $100 \mathrm{~kJ} / \mathrm{m}^{3}$.

\section{Hydraulic fracturing as a pre-conditioning method at El Teniente}

The expert literature describes hydraulic fracturing as a fracturing method capable of causing a single fracture in the plane orthogonal to the minor tectonic stress " $\mathrm{O}_{3}$ " (at El Teniente this implies a subhorizontal fracture). Its extension in the plane that contains the intermediate stress " $\mathrm{\sigma}_{2}$ " and the principal stress " $\sigma_{1}$ " (according to 2018 practices at El Teniente) reaches a $20 \mathrm{~m}$ radius. Its operative frequency implies 1 fracture every $1.5 \mathrm{~m}$. Approximately $0.7 \mathrm{FF} / \mathrm{m}^{3}$ is added to the natural in-situ CMET FF.

According to Jaeger et al (1969), the strain energy $\mathrm{W}_{\mathrm{c}}$ of a fault with hydraulic fracturing characteristics happens in a plane according to the following expression:

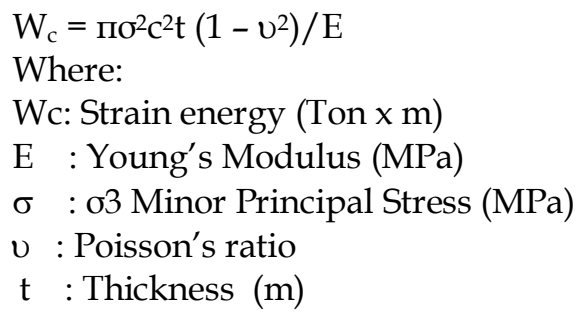

For fractured hydraulic pre-conditioned rock in CMET, Poisson's ratio and Young's modulus have a value of 0.2 and $53 \mathrm{GPa}$ respectively, and the applied stress 03 is $30 \mathrm{MPa}$.

The fractures generated by the hydraulic fracturing considers a circular area with a diameter of $40 \mathrm{~m}$, with a volume derived from the thickness " $\mathrm{t}$ ". Estimating $\mathrm{t}=0.0001 \mathrm{~m}$ results in the following:

- $\quad 18.840 \mathrm{~m}^{3}$ volume of rocks with SED $=212 \mathrm{~kJ} / \mathrm{m}^{3}$ (very high risk) contained between each hydraulic fracture. (spacing every $1.5 \mathrm{~m}$ ).

- The pre-conditioning volume assigned to each hydraulic fracture has a magnitude of $0.125 \mathrm{~m}^{3}$.

- The value of Wc is 0.812 Ton $x \mathrm{~m}$, equivalent to $8.12 \mathrm{~kJ}$ in the $0.125 \mathrm{~m}^{3}$ of hydraulic fracture.

- This is equivalent to $65 \mathrm{~kJ} / \mathrm{m}^{3}$, but this magnitude acting only in the $0.125 \mathrm{~m}^{3}$ attributable to the failure caused by hydraulic fracture.

In summary only $0.125 \mathrm{~m}^{3}$ of $18.840 \mathrm{~m}^{3}$ have been subject of SED reduction (from 212 to $65 \mathrm{~kJ} / \mathrm{m}^{3}$ ) changing its vulnerability state to moderate. The rest of the CMET rock volume remains with the same rockburst potency (very high risk).

In our opinion, pre-conditioning with hydraulic fracturing has a series of operational limitations:

- $\quad$ Spacing every $1.5 \mathrm{~m}$. reach (according to 2018 practices at El Teniente).

- $20 \mathrm{~m}$ reach (according to 2018 practices at El Teniente).

- Orthogonal orientation with respect to the lesser tectonic stress.

This limits the deterioration action in terms of strain energy.

The above does not diminish the positive effect that hydraulic fracturing provides at mine-scale in order to accelerate the caving in upper levels while reducing the magnitude of the seismic events in the caving process. Nevertheless, according to the proposed analytical evaluation, hydraulic fracturing would be insufficient to mitigate rockbursts at mine design-scale. 


\section{Determination of strain energy fracturing to mitigate rockbursts}

Without mentioning the actual reference, Talobre (1957), refers to R. Fenner's suggestions about the occurrence of fractured rock halo around excavations (See Figure 3).

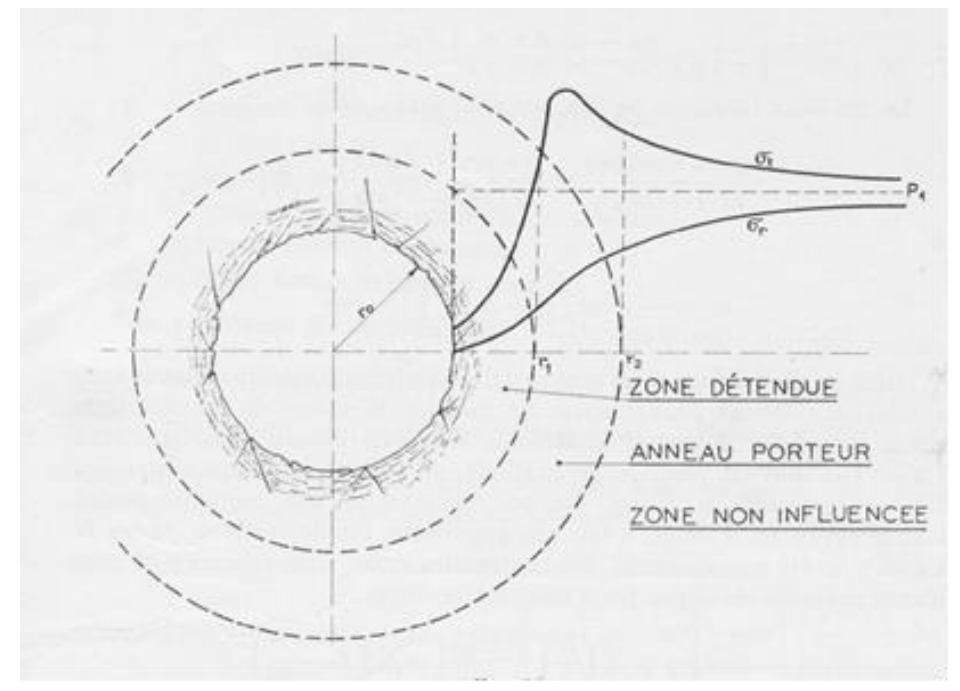

Figure 3. Fractured material halo in excavation contours

In order to mitigate rockbursts, Fenner suggests the following :

- The presence of the Zone Detendue will diminish the magnitude of the stresses over the excavation.

- The Zone Detendue will have a lesser strain energy.

- If a rockburst event happens in deep intact rock, the seismic pulse will be buffered by the fractured halo.

From the above, it might be appealing to evaluate the sufficiency of strain energy in the fractured halo to mitigate rockbursts. This evaluation requires relating the Zone Detendue deterioration or rock fracturing with the strain energy of this rockburst-prone rock.

From pre-conditioning related studies literature available at CODELCO, the studies of acoustic records in UCS samples of Andina's 3rd Panel. (Codelco reference: Theoretical Support for PC IM2-2009) are highlighted, where 3 spatial perspectives of acoustic events during UCS tests are shown in Figure 4.
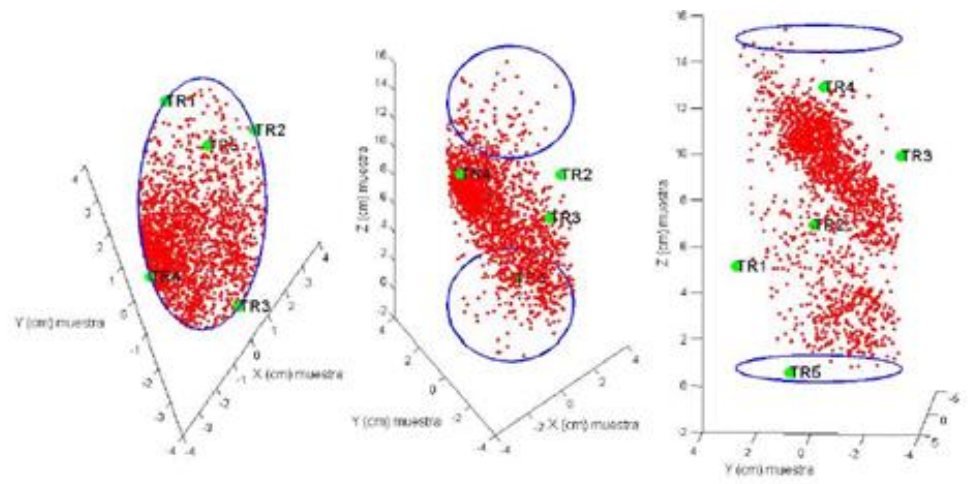

Figure 4. Acoustic events from 4 triaxial sensors 
The above figure shows two effects related to the explosive rupture phenomenon in the rocks:

- Acoustic events are a manifestation of the cracking that reduces the rock's competence.

- The acoustic events are aligned following a typical UCS rupture angle.

The study by CODELCO IM2-2009 does not perform a balance of energy of the rocks during the UCS process, but such balance can be obtained by a computational simulation of the UCS test.

Figure 5 shows the output results of an ALCODER finite elements model, Krstulovic (2004), which includes Love's (ED formula 1) algorithm for the determination of strain energy. In this case, knowing ED's magnitude of $220 \mathrm{~kJ} / \mathrm{m}^{3}$, in the explosive rupture of a granite sample, the ALCODER's output automatically colours the elements above that maximum strain energy value during the UCS loading process at different percentages of maximum applied load.

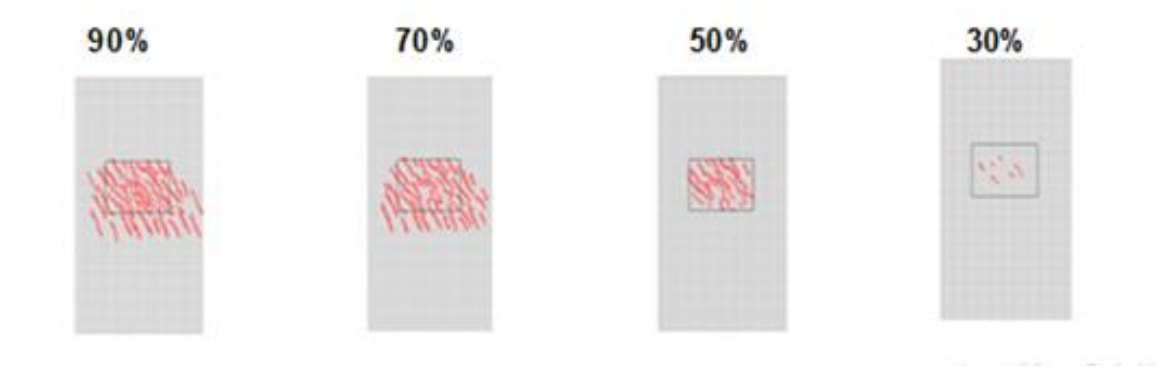

Figure 5. ALCODER finite elements results for ED during UCS loading process

The results of this simulation lead to the following: conclusions:

- As in the case of acoustic energy, the failed elements because of exceeding the admissible ED threshold are aligned in a similar angle to the typical case of lab tests.

- As of $30 \%$ of UCS loads, a notorious increase in the number of failed elements is observed.

A graphical representation of UCS/ED is shown in Figure 6, which shows that in this granite at $60 \%$ of maximum UCS load, $25 \%$ of its volume has been fissured because of non-admissible ED. In other words, at $60 \%$ of UCS rupture load, this rock is damaged in $25 \%$ of its total volume, which suggests a diminution of its quality indexes. This assertion is well documented in a series of publications by different authors that summarize the work of Eberhardt (1998).

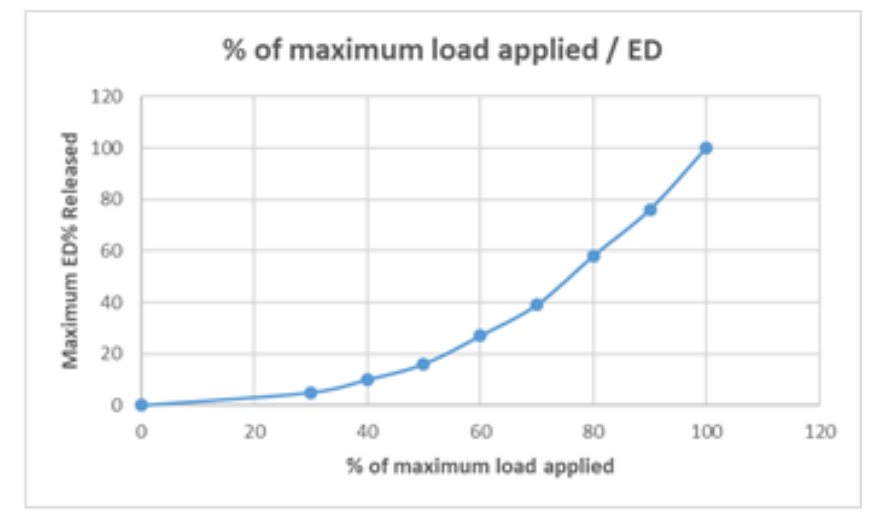

Figure 6. \% of maximum load applied/ED

Based on the above, a strain energy counter of fissured rock is obtained. 


\section{PRELIMINARY CONCLUSIONS}

The results based on the concept of strain energy indicate that hydraulic fracturing in its current modality is insufficient to mitigate rockburst events at a local drift-scale, even though it reduces the magnitude such an event would trigger. These studies suggest that the mitigation by strain energy deterioration of these rocks, has to be via massive fissuring without implying the explicit rupture of the hydraulic fracture.

The authors suggest that the requirements of massive fissuring have to be achieved through the direct application of a tool in the rock neighbouring the drift roof and walls, as stated by Talobre (1957). This Plasma tool fissures the rock by using thermal pulse without causing an exposed fracture in it. The first analytical revisions of the strain energy deterioration caused by this thermal pulse are shown in Figure 7 , where the attenuation of the plasma strain energy effect can be noted based on the initial point of the pulse.

The preliminary analytical results are in experimental verification stages.

According to this strain energy analytical formulation, the hydraulic fracturing does not cause enough deterioration in order to stop rockbursts occurrences in the rock mass. The rock mass should be preconditioned before developing the excavation.

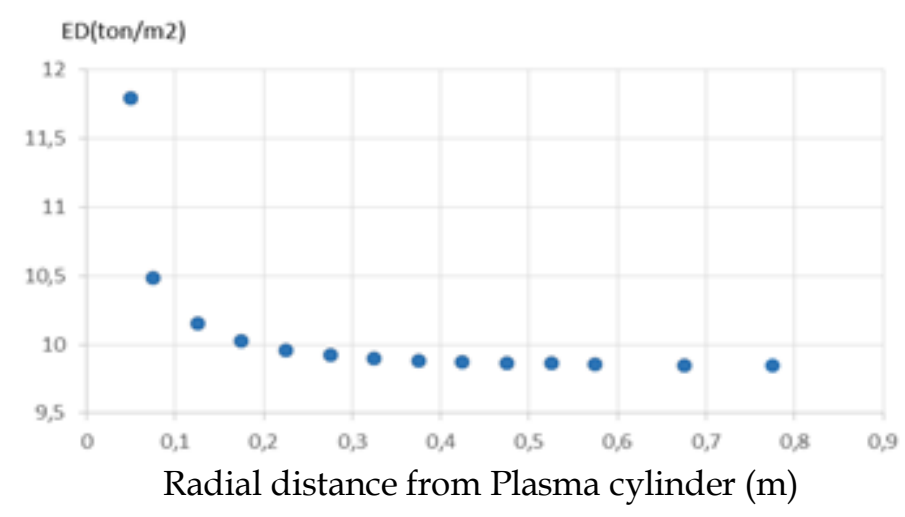

Figure 7. ED attenuation related to thermal pulse 


\section{REFERENCES}

Eberhardt, E. B. (1998). Brittle rock fracture and progressive damage in uniaxial compression. Saskatchewan, Canada: University of Saskatchewan. Obtained from https://harvest.usask.ca/handle/10388/etd-10212004-001228?show=full.

Jaeger, J., C Cook, N. G., and Zimmerman, R. (1969). Fundamentals of Rock Mechanics. John Wiley \& Sons.

Lianyang, Z., \& Einstein, H. H. (2 de 2004). Using RQD to estimate the deformation modulus of rock masses. International Journal of Rock Mechanics and Mining Sciences \& Geomechanics Abstracts, 41(2), 337-341. doi: 10.1016/S1365-1609(03)00100-X.

Palmstrom, A. (3 de 2005). Measurements of and correlations between block size and rock quality designation (RQD). Tunnelling and Underground Space Technology, 20(4), 362-377. doi: https://doi.org/10.1016/j.tust.2005.01.005.

Priest, S. D. (1993). Discontinuity Analysis for Rock Engineering. Australia: Chapman \& Hall. doi: https://doi.org/10.1007/978-94-011-1498-1.

Sirait, B., Wattimena, R. K., \& Widodo, N. P. (2013). Rockburst Prediction of a Cut and Fill Mine by using Energy Balance and Induced Stress. (K. Matsui, \&S. Kramadibrata, Edits.) Procedia Earth and Planetary Science, Volume 6, 426-434. doi: https://doi.org/10.1016/j.proeps.2013.01.056.

Talobre, J. (1957). La mécanique des roches: appliqué aux travaux publics. DUNOD.

Wang, J.-A., \& Park, H. (2001). Comprehensive prediction of rockburst based on analysis of strain energy in rocks. Tunnelling and Underground Space Technology, 16(1), 49-57. doi: https://doi.org/10.1016/S0886-7798(01)00030-X.

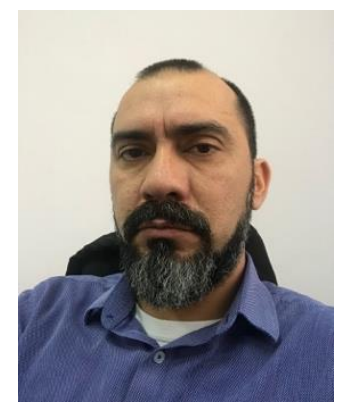

\section{Rodrigo Zepeda Araya}

Geomechanical Engineer

Codelco-Chile

Geomechanical Engineer with 12 years of experience in underground mining. Project manager of Geomechanical research for El Teniente Division. 